\title{
FLOTAR SIN MÁSCARA DE AMAEM MARÍAS GUERRERAS
}

\author{
Alicia Casado Vegas \\ alicastoyota@yahoo.com
}

\section{AMAEM. MARÍAS GUERRERAS}

Flotar sin máscara (Madrid, Ediciones Irreverentes, 2018) es hasta ahora la última publicación de la Asociación de Mujeres de las Artes Escénicas de Madrid, Marías Guerreras, que contiene cinco textos dramáticos escritos por mujeres, como reza el subtítulo del libro. Se trata de una edición bilingüe traducida al inglés por Andrew G. Hargreaves, Marina Castiñeira, Amaya Cuevas, Blanca Pascual y Laurie L. Urraro.

En sus casi veinte años de andadura, Marías Guerreras ha sido fiel a su lema de nacimiento de visibilizar el trabajo de las mujeres en la escena con una evidente perspectiva de género. Desde Tras las tocas, su primer montaje, hasta el reciente Silenciadas, pasando por otros como No más lágrimas o Exorcismo de sirena, esta asociación -integrada por una diversidad de directoras, actrices, dramaturgas, investigadoras, escenógrafas, iluminadoras, técnicas de sonido, regidoras, tramoyistas, músicas, bailarinas...- ha ofrecido su palabra, su cuerpo y su voz para poner de relieve y criticar los problemas a los que se enfrenta la mujer en la sociedad actual: el olvido, la desigualdad, los prejuicios, la represión de su sexualidad, la identidad de género, la incomprensión, la inmigración, la derrota, la guerra, la enfermedad, la violencia machista o el abuso sexual. Su voz se ha canalizado como carcajada o susurro, como canto o llanto, como risa o dolorido silencio e incluso como grito, tal como rezaba otro de los títulos de sus primeros montajes: He dejado mi grito por ahi. ¿Lo habéis visto? (2012); y estas notas de sororidad se han propagado lo mismo en las tablas de la farsa que en una tribuna universitaria, en la populosa barra de un bar o en el tímido papel de un libro.

En efecto, desde su fundación un 22 de marzo de 2001, Marías Guerreras no solo ha creado y producido espectáculos, sino que, además, coherente con su faceta pedagógica, ha realizado ciclos de actividades y publicado libros como I Ciclo de las actividades de las Marias Guerreras en Casa de América (El Astillero, 2004), Mujeres en seis actos (Castalia, 2005), De la vanguardia a la memoria (Castalia, 2006), Evolució. Exorcismo de sirena (Primer Acto, Teatro de Papel, 2008) y el 
que ahora comentamos ${ }^{1}$. Los tres primeros son misceláneas de textos dramáticos, homenajes o artículos de investigación con fotografías a modo de documento que atestiguan el fragor creativo de estos ciclos, y los dos últimos están focalizados en nuestra labor dramática con la curiosidad de que el volumen publicado por la editorial Primer Acto contiene, junto con una obra de un miembro de la asociación, el texto Evolució de Aina Tur, que testimonia otra de sus características, que es la de compartir y colaborar con otras asociaciones que poseen el mismo enfoque, en este caso, con el Projecte Vaca de Barcelona, con el que se realizó un intercambio en la madrileña sala Cuarta Pared en febrero de 2008.

Flotar sin máscara nace precisamente de esta necesidad de compartir y de aniquilar fronteras.

Este trabajo empezó a gestarse con la lectura dramatizada de Anónima empatía (Anonymous empathy) en Brighton un mes de marzo de 2012 amparada además por el Woman's Centre y las Feminists of Brighton. La metáfora del título hace referencia a la idea de la entrega azarosa de unos fragmentos de alma que nacieron vertidos en el molde del idioma español para ser enmascarados o traducidos a otra lengua con la pretensión de ser recibidos ${ }^{2}$. No obstante, si nos fijamos en la traducción inglesa, floating with no mask, también puede connotar riesgo o peligro en el sentido de dejarse perder en una corriente de agua sin ningún tipo de protección, en la medida en que mask significa además "gafas para bucear».

Este libro recoge cinco textos escritos por cinco mujeres integrantes de la asociación, cuatro de los cuales han sido objeto de numerosas representaciones. Como curiosidad, este volumen va precedido por dos prólogos: una introducción realizada por Marina Castińeira sobre la aventura de la traducción y un prólogo titulado "Escribir teatro en un tiempo líquido", en el que se hace una breve reseña de los textos y se plantea una reflexión sobre en qué medida refleja el teatro contemporáneo, y en concreto el nuestro, esa cosmovisión propuesta por el reconocido sociólogo polaco Zigmunt Bauman que él ha denominado «vida líquida».

${ }^{1}$ Esta enorme labor ha sido reconocida con varios premios como el Premio XVII Muestra de Teatro, Torreperojil en 2002, el Premio Fundación Carolina Torres Palero en Valencia, en el año 2005, Premio Palma de Alicante en 2014 o el Premio Rosa María García Cano en 2017.

2 Así lo expresa la propia Marina Castińeira en su introducción: «Con ellos y otros, mediante este libro, nuestras conversaciones se posicionan en un área amplia de comunicación con ambición transcultural: deseamos que el intercambio nos siga ayudando a tener presencia y a ser comprendidos; a la vez que a comprender mejor a otros y a nuestra propia cultura a través del teatro. Este es el fin último de nuestro proyecto. $\mathrm{Y}$ en su procesamiento, al traducir para compartir nuestro teatro, reelaboramos poco a poco nuestro cosmos de entendimiento a partir de palabras robadas, de sueńos reconstruidos por la conciencia en otra lengua, y con los que polinizar en otro lugar. Por eso, podríamos decir, como lo hacía Rainer M. Rilke - por citar a uno de mis poetas favoritos- en una carta al traductor polaco de sus Elegías, que "somos las abejas de lo invisible", que flotamos sin máscara. Con relaciones de palabras y emociones erigimos etéreos microcosmos orgánicos, a los que, más tarde, sin embargo, la puesta en escena deberá conferir -incluso en sentido estricto- rotunda, fértil y eficiente visibilidad» (II). 
El primero de los textos de creación corre a cargo de la actriz Blanca Ortiga ${ }^{3}$, que desde 2007 es creadora de sus propios espectáculos.

\section{IM-POSTURA}

Im-postura, de Blanca Ortiga, mereció la puesta en escena, bajo el título aPnea, en los teatros del Canal de Madrid en septiembre de 2013 en el marco del Festival $A$ solas, un festival transcultural de solos teatrales de mujeres promovido desde el continente americano por el Magdalena Project, en el que también participó el Projecte Vaca de Barcelona.

Es una obra sin texto, una acción escénica en un acto breve, citando a la autora, en la que la palabra se utiliza tan solo para fijar en forma de acotación el diseño de una partitura de movimientos.

El título hace referencia al crisol de estereotipos que injustamente se han impostado sobre la mujer, que denotan ignorancia, menosprecio y desdén. Al separar el prefijo Im- en el título la autora está haciendo hincapié en ese movimiento de fuera hacia adentro que como una espada se clava en el cuerpo de la mujer impidiéndole el gesto contrario de irradiar su propia, intransferible e inasible identidad, que es lo que pretende mostrar Blanca Ortiga con este acto performativo. Pero este cuerpo irá acompañado por el sonido de la música de un piano en directo: Litanias of Satan de Diamanda Galas. Y así estas letanías serán el detonante para hacer renacer el alma de ese cuerpo históricamente enajenado meciéndolo hasta la convulsión para arrancarle su propia voz. De ahí que sus notas queden solapadas por un gemido que brota desde lo más hondo de ese cuerpo-alma y del que en un principio se excusa con un «oops» al darse cuenta de que se ha desnudado delante de un público, como si se le hubiera escapado una ventosidad y se viera obligada a cumplir con las normas de cortesía impuestas. Sin embargo, esto es solo una pose. Me permito anotar este momento para subrayar por tanto otra connotación evocada por el título «im-postura», relativa a la paranomasia de esta palabra con «impostora», y que contribuye a la autoafirmación y al empoderamiento del personaje denominado MujER:

Esta expresión, «Oops!» trata de generar ambigüedad este personaje conocía perfectamente ese mundo interior (performado no solo en lo físico, sino también en lo intelectual) y no se arrepiente del mismo, simplemente "se le ha escapado" públicamente. Esta acción, este tratar de recolocarse para una audiencia, para ese espacio social, y disimular esta descomposición que acaban de ver los espectadores, evidencia una distancia entre la mujer social, y su imagen creada, con la mujer intima (CASADO et al. 26).

${ }^{3}$ Blanca Ortiga es licenciada en Arte dramático y en Ciencias políticas. Con amplia formación en Espańa y en el extranjero, colabora en revistas de teatro e imparte talleres a mujeres en riesgo de exclusión social. Para más información sobre las autoras remito a la página web de Marías Guerreras. 
Al eliminar el lenguaje articulado, el cuerpo de la actriz (la propia Blanca Ortiga) no solo queda sobredimensionado, convirtiéndose en el único foco de atención, sino que se comunica que la irracionalidad vital es más auténtica que las producciones racionales u ordenadas de la cultura. El cuerpo de Mujer ha recuperado un alma que ansía expresarse con plena libertad y ese último gesto de aparente espontaneidad es un juego con o contra el espectador, al que utiliza y del que, a veces, se burla.

No insistiremos más en que Im-postura es una performance reivindicativa, que exhibe impúdicamente la egocéntrica soberbia de un personaje Mujer que necesita afirmar su yo, su especificidad, su libertad y su despojamiento de todo lo que una tradición patriarcal le ha dejado impresa. Tampoco es casual, por tanto, que el siguiente de sus montajes, amparado también por AMAEM, que lleva el significativo título de aPnea, hable de algo tan primario y puro como la respiración en tanto que proceso para descubrir el propio yo, y que lleve por subtítulo «la de-construcción como única salida»

\section{2015, REGRESO AL PASADO}

2015, regreso al pasado (2015, back to the past) es una obra de Alicia Casado ${ }^{4}$, de carácter político, que se define en el índice como «una distopía social cómico grotesca» (CASADO et al. 5).

El feminismo está patente en su afán visibilizador del lesbianismo, que es víctima de un mayor silenciamiento. Por tanto se elige como protagonistas a dos mujeres casadas que reciben en su propia casa la kafkiana visita de un inspector del Ministerio del SIRE (Sanidad, Interior, Religión, Educación) y un juez para aplicar una nueva ley, llamada la Ley de Terrorismo Moral, que parodia la vieja ley franquista llamada de peligrosidad social, en la que, entre otras lindezas, se condenaban las relaciones homosexuales, dando por entendido que afectaban solo a los hombres y silenciando perversamente la existencia del lesbianismo. Pero no es una obra excluyente, ya que incluye también personajes homosexuales masculinos que tienen una gran incidencia en la trama.

Fue escrita en el año 2011 al calor del anuncio de la convocatoria de elecciones anticipadas por el gobierno de socialista de José Luis Rodríguez Zapatero para el día 20 de noviembre de 2011, por lo que en un primer momento nació con el título de $21 \mathrm{~N}$, el día después.

Para muchos la Ley del Matrimonio Igualitario de julio de 2005 fue uno de los mayores logros del PSOE de Zapatero en materia de derechos sociales. Sin

${ }^{4}$ Alicia Casado es doctora en Filología y licenciada en Dramaturgia. Ha participado en congresos, colaborado en revistas especializadas (Dicenda, Primer acto, Acotaciones) e impartido cursos y talleres. Como dramaturga ha publicado, además, Exorcismo de sirena, El salto de Léucade, El pez que lloraba dentro de su pecera, Seven eleven de la disponibilidad, Carta a un maltratador y El caballero de Fuentevaqueros. 
embargo, como era de suponer, esta ley suscitó cataratas de disidencia que caían en forma de opiniones que iban desde la argumentación más o menos razonada sobre el concepto y la etimología de la palabra «matrimonio» al insulto o al chiste de estilo de aquellas declaraciones de una política del Partido Popular, que llegó a ser alcaldesa de Madrid, que parecían querer comparar las uniones homosexuales con las uniones de manzanas o peras. En otro lugar he señalado cómo este desafortunado o divertido símil, según se mire, cacareado en el 2004, dio lugar también a réplicas en la escena teatral contemporánea en montajes como el de Chicas de Carmen Losa, de junio de 2005, o en los Monólogos de bollería fina de Mariel Maciá, estrenados tres años después en Madrid (CAsado, Teatro lésbico 28).

Naturalmente, estas reacciones del Partido Popular no tardaron en formalizarse en un recurso contra dicha ley al Tribunal Constitucional, pero los siete años de demora de su respuesta irían sembrando no pocas inquietudes a los recién surgidos matrimonios homosexuales, que podían ver transformadas su ilusión y valentía iniciales en una pura incertidumbre: si ganaban el recurso ¿qué pasaría con esos más de dos mil matrimonios igualitarios que se habían visibilizado en España? ¿Se anularían de un plumazo? ¿Se perdonarían los ya existentes como un mal menor? Y si el 20 de noviembre de 2011, a causa de la llamada crisis económica, sucedía lo previsible, que era la victoria del Partido Popular, ¿se atreverían a incluir entre su proyecto innovador de reformas la reformulación de la vieja Ley de Peligrosidad Social mediante la novedosa inclusión de las mujeres lesbianas, que habían sido ignoradas e invisibilizadas completamente por esta ley franquista?

INSPECTOR: Ya veo la naturaleza de su enfermedad. Soy el inspector encargado de su caso. Sólo quiero ayudarles. Nuestra estimada presidenta ha reformado la Ley del Santo Sacramento del Matrimonio y ha recuperado, por supuesto adaptándola a la vanguardia de los nuevos tiempos, la Ley de Vagos y Maleantes de 1933 y la Ley de Peligrosidad Social de 1970, por lo que... (CASAdo et al. 35).

¿Y si, como veremos en este fragmento, arrobados por la euforia reformista, en este contexto innovador, fueran capaces de idear un proyecto arquitectónico puntero para transformar el céntrico barrio de Chueca en, por ejemplo, algo así como un barrio snob o, mejor, en una magnífica Villa Olímpica?

IRENE: Lola por favor, firma, pediremos ayuda al COGAM.

INSPECTOR: (Se sonríe). Su ingenuidad me sorprende señorita. ¿¿A una asociación ilegal? Los vecinos de Chueca serán expropiados y pasarán a disposición judicial. La Presidenta lo convertirá en una moderna Villa olímpica. (Le suena el móvil, música de Händel. Al Juez). Si me disculpas un segundo (CASADo et al. 37).

Estas son algunas de las preguntas a las que en tono humorístico casi farsesco pretendía dar respuesta mi texto $21 \mathrm{~N}$, el día después.

Pero, como sucede como muchos textos teatrales, este no tuvo la fortuna de ser representado, por lo que, como obra de circunstancias, quedó en un cajón hasta que la energía de la asociación Marías Guerreras y el apoyo de la SGAE y de la valiente editorial Irreverentes creyeron en el proyecto de publicación del libro colec- 
tivo Flotar sin máscara. Dado que la literatura de compromiso social suele quedar a la deriva para asumir el riesgo de diluirse con el tiempo que la vio nacer, como corría ya el año 2018, con mayor o menor fortuna, hube de realizar pequeños cambios, uno de los cuales afectaba al título ahora 2015, regreso al pasado, que se ofrecía como una pieza de teatro de política-ficción en la que se imaginaba un momento en la historia de un país, no difícil de identificar con el nuestro, en el que una ley anula el matrimonio homosexual y obliga a los homosexuales a someterse a un tratamiento médico para curarse de su pretendida enfermedad. La fecha de 2015 pretendía hacer un guiño al receptor para que se situara en las últimas elecciones que dieron el gobierno a los conservadores. Y hasta ahí, en el año 2018, la obra se quedaba aparcada en una distopía, ya que, afortunadamente, los hechos que se planteaban no habían sucedido.

Pero podrían suceder...

Zygmunt Bauman señala que estos tiempos líquidos cuestionan la ingenuidad de la cosmovisión ilustrada de la creencia en el progreso, y algunos acontecimientos recientes de la vida espańola están dando muestras de la existencia de un no poco poderoso sustrato de oscurantismo cuyos frutos podemos ver en gestos como el del obispado de Alcalá de Henares, que sigue considerando a los homosexuales como enfermos cuando, desde mayo de 1990 la homosexualidad ha sido eliminada de la lista de enfermedades mentales de la Organización Mundial de la Salud. Sobre este desinterés, como sabemos por eldiario.es, desde abril, este obispado está patrocinando cursos para curar a los homosexuales.

Ante la denuncia de FACUA a la Consejería de Políticas Sociales y Familia de la Comunidad de Madrid, el obispado ha respondido asegurando que «no renuncia a acoger y acompañar a las personas que libremente lo solicitan" y que se trata de "ayuda y orientación» solicitada por personas y que «dicho acompañamiento integral, pastoral y espiritual en ésta como en todas las materias, siempre se hace desde la fe y la razón, con amor y verdad a la luz de la Palabra de Dios y del Magisterio de la Iglesia Católica». Es decir, el obispado esgrime el argumento de la ayuda generosa para justificar lo que, en mi opinión, sería un gesto de violación o terrorismo psicológico5.

Pues bien, este episodio de la reeducación estaba ya en mi obra, que, aumentando la broma, sitúa la sede de los cursos en la Cruz de los Caídos, lugar que, por otra parte, se ha vuelto de máxima actualidad con motivo de la exhumación de los restos de Francisco Franco y que ha dado alas y alientos a ese sustrato al que me acabo de referir.

Tras la súbita implantación de la nueva ley a las protagonistas solo les quedan dos opciones, o firmar «voluntariamente» la nulidad de su matrimonio como prólogo a la realización de dicho reparador cursillo, o la cárcel.

Como muestra me permito anotar unas palabras del arranque del texto:

${ }^{5}$ En el contexto de la violencia de género, abordo el tema del lavado de cerebro en mi obra El pez que lloraba dentro de su pecera, publicado por la editorial Fundamentos en 2013. 
Encienden la televisión. Se oye el final del himno nacional.

Locutor: Buenos días. Comenzamos este avance informativo para anunciar que el Parlamento acaba de aprobar por mayoría absoluta la nueva Ley de Terrorismo Moral con el fin de apartar temporalmente de la vida social al individuo peligroso y darle tratamiento y educación para lograr su readaptación a la sociedad. Los órganos judiciales... (CASADo et al. 30).

También la humanidad y la generosidad eran los argumentos en los que se basaba mi personaje ideado en el 2011 como representante del gobierno y que pronunciaba estas palabras que salían del televisor de las protagonistas para explicar algunos apartados de esta nueva Ley de Terrorismo Moral:

VOZ DE LA PRESIDENTA: ... moral con el objetivo humano y social no sólo limitado a defender a los ciudadanos españoles y españolas honrados sino para lograr la plena integración de los hombres y de las mujeres que han quedado marginados de una vida ordenada y normal. Esta ley incluye la anulación de las uniones en contra de la natura y creará establecimientos de reeducación para quienes realicen actos de homosexualidad... (CASAdo et al. 31).

Ni que decir tiene que este cursillo será impartido por uno de los máximos expertos en este campo; en este caso por el inspector del SIRE, el recién creado Ministerio de Sanidad, Interior, Religión y Educación:

InSPECTOR: Ya veo la naturaleza de su enfermedad. Soy el inspector encargado de su caso. Sólo quiero ayudarles. Nuestra estimada presidenta ha reformado la Ley del Santo Sacramento del Matrimonio y ha recuperado, por supuesto adaptándola a la vanguardia de los nuevos tiempos, la Ley de Vagos y Maleantes de 1933 y la Ley de Peligrosidad Social de 1970, por lo que... (CASAdo et al. 32).

En el 2011 el acicate para crear este conflicto fue también el descubrimiento del libro de Richard Cohen titulado Comprender y sanar la homosexualidad (2004), que con estupefacción consulté en internet y del que luego supe que también fue objeto de una denuncia por parte de los colectivos de gais y lesbianas, que consiguieron en diciembre de 2011 eliminar este libro de los estantes de la librería de El Corte Inglés ${ }^{6}$. Pues bien, precisamente parece que este libro está en las estanterías del obispado y vuelve a ser de actualidad. Richard Cohen da la solución con la receta de los consabidos pasos que se resumen, en un derroche creativo, en el acrónimo HALT. En lugar de citar el libro de Cohen me permito utilizar las palabras de uno de mis personajes:

JuEz: (Entregándole otro papel a Irene). Con esta firma se compromete a realizar el Programa de rehabilitación y se somete al tratamiento HALT. En el reverso se explica en qué consiste.

${ }^{6}$ https://cadenaser.com/ser/2011/12/27/sociedad/1324955616_850215.html. 
Inspector: (Recita como de memoria). Hungry, Angry, Lonely, Tired (Casado et al. 38).

Por eso las sesiones en el Valle de los Caídos comenzarán siempre con la pregunta de control, sugerida por el texto del también experto Richard Cohen, que en el prólogo de su libro demuestra la eficacia de su método, ya que él mismo se curó así de su propia homosexualidad:

INSPECTOR: La persona humana necesita que todos los días se reafirme en ser querida por ser hija de Dios. ¿Hay alguien que quiera redimirse contando si ha recaído? (Largo y tenso silencio). Recuerdo que si habéis caído en la tentación debéis haceros la pregunta de control: jestoy hambriento, enfadado, solo o cansado? Y que la masturbación es una mala medicina emocional utilizada para no sentir la herida, el dolor o la decepción. Pero no cura. (Pausa). Entonces demos la bienvenida a Irene. Levántese señorita y cuéntenos su historia. Está en familia, somos todos hijos de Dios y nadie va a juzgarla; el que esté limpio de culpa que tire la primera piedra (CASADO et al. 42).

Es decir, el proceso del enfermo homosexual pasa por las fases del hambre de otro cuerpo, la ira, la soledad y el hastío, aspectos para cuya mejora Cohen aporta soluciones más que peregrinas. dia:

Por supuesto la Iglesia legislando en la sombra no podía faltar en esta come-

InSPECTOR: Buenas tardes. Desde aquí mandamos la enhorabuena al padre Maravillas que en estos momentos está teniendo el honor de ser investido Doctor Honoris Causa por la Universidad Obispicia de Puntillas. (Mirando a Irene). Vamos a rezar una oración para suplicar a Dios que les mantenga alejados del vicio y de la enfermedad. Las manos. (Todos se cogen de las manos, el Inspector se da cuenta de que dos hombres se han puesto juntos y se aprietan muy fuerte, en un gesto brusco pero sonriendo les separa y pone en medio a una mujer). Hermana, tome su guitarra y dé la nota (CASADO et al. 41).

Una comedia casi grotesca llena de ironía que no duda en revelar la identidad gay de los mismos brazos ejecutores de la justicia, como el inspector, que fue alumno del mismísimo Cohen y al que posteriormente confiará a su propia hija, quien después del tratamiento saldrá absolutamente desorientada.

En suma, $21 \mathrm{No} 2015$ supera la circunstancia que la vio nacer para hablar de un mal eterno como es el de la intolerancia. 
Aprendiendo a vivir ( $O$ de cómo Pinotxa encontró a Dogot) es una obra estrenada el 8 de mayo de 2005 escrita y dirigida por Margarita Reiz ${ }^{7}$ e interpretada por Sara Martín y Javi Rufo con la música de Marta Alonso, cuyas partituras aparecen también publicadas en el libro.

Alberga una recreación contemporánea del mito ovidiano de Pigmalión en la que, en consonancia con nuestro tiempo, el artífice pasa de ser escultor a convertirse en un científico, y la estatua abandona la piedra para acoger a los cables y al metal. Esta creación se presenta como una obra de carácter multidisciplinar para todos los públicos y tiene por objetivo la transmisión de valores.

Es una historia con final feliz en la que un sabio excéntrico, mezcla de payaso, doctor Frankenstein y del Geppetto del relato de Collodi, crea una niña cíborg con la finalidad de que cobre vida y se humanice. No sin intención, este científico, tildado de loco, se llama Zepeto, y se adjudica también la animación de otros personajes:

¿La veis? Yo la inventé. Sí, he inventado muchos seres inanimados en mi larga historia. Comencé con un tal Pinocho, que era de madera y se hizo niño de carne y hueso cuando aprendió a vivir porque se amaba y respetaba. ¿Bonito, no...? Yo amo a Pinocho y también la amo a ella: Pinotxa (CASADO et al. 70).

El proceso de la conquista de la vida humana naturalmente implica la existencia de un corazón con todo lo que este conlleva de alegría y tristeza, y el sentimiento más importante habrá de ser el amor hacia uno mismo.

Por eso, antes de ser humana, la nińa cíborg juega y habla con su amigo invisible, al que llama Pepito, y le comunica que no se gusta a sí misma, aprovechando para realizar una crítica a una parte de la sociedad que establece como referente un determinado, enfermizo y rancio estereotipo femenino.

En esta cita se destaca el primero de los tres ideales esenciales que se destilan en la función: la autoestima, que será requisito indispensable para que la niña cíborg se convierta en humana. Si una persona no se ama a sí misma todo el amor que reciba será inútil.

El segundo valor es la fuerza de la ilusión, la confianza en uno mismo, que tiene mucho que ver con el anterior porque, aunque los demás deseen que nosotros poseamos algo, si nosotros no albergamos esa fe, aunque lo tengamos, no seremos capaces de verlo.

Y el tercero es la fuerza de la unión, la solidaridad con los otros, la búsqueda de lo que nos une frente a lo que nos separa para construir desde ese pilar un mundo más habitable.

7 Margarita Reiz es doctora y licenciada en Dirección de escena. Ha impartido cursos y talleres, así como colaborado en congresos y revistas especializadas como ADE, Acotaciones o Primer acto en calidad de redactora jefe y en su consejo de redacción. En su labor de directora destaca el montaje de Juana Delirio. 
Además de esta lectura, digamos, existencial, este texto nos conduce a una lectura en clave social. Acabamos de citar el concepto de solidaridad, que condensa perfectamente el número musical de la función: Juntos, del que transcribo un puñado de versos:

Juntos luchar.

Juntos despertar.

Hay que mirar el lado bueno,

pequeñas cosas te hacen feliz,

como estar junto a ti...

Hoy es el día de cambiar esta sociedad,

porque no tiene dinero ni hogar,

hay mucha gente que no tiene ná,

y los de arriba siempre quieren más

porque todas las personas tengan,

educación, sanidad,

nosotros queremos cantar,

que cambie este circo internacional, transforma la guerra en

buen rollo y paz (CASADO et al. 102).

Por supuesto no carece la obra del ingrediente musical ni de la transcripción de las partituras originales compuestas para piano. Podría decirse que la obra en sí misma es una partitura no cerrada ofrecida, además de para ser cantada y danzada, para ser enriquecida por la magia y las payasadas del mago Zepeto, por el mimo y las acrobacias en el aro y la tela de la actriz que interpreta a la nińa y por las ansias de participación del espectador, que contesta, canta o salta al escenario. Hay pues un aire de improvisación que armonizaría con el concepto de un arte líquido.

Pese a que el receptor preferente es el niño, esta obra juega con la poesía de la ingenuidad para dotar de polisemia a los diálogos ingenuos de los pequeños que todavía no han entrado en el juego de la vida de los humanos:

Pepito: ¿Qué es eso?

Pinotxa: ¿La Paz...? (83).

Y no podía faltar la lectura en clave feminista, a la que ya hemos aludido. En primera instancia la protagonista es una mujer niña que sin haberse convertido en humana ya sabe de las desigualdades de género a las que finalmente no quiere jugar:

Pinotxa: (Pausa. Para cambiar de actitud de pronto se la ve exageradamente alegre). ¿Jugamos a los chicos y a las chicas? Yo hago de chico, ¿vale?

Pepito: Pero tú no tienes..., cosita.

Pinotxa: (Después de otra pausa). ¿¿Te mando yo o me mandas tú?

Pepito: Así es que eso era lo que querías: ponerte por encima de mí. Mandarme.

Pues vale, pero luego te mando yo a ti y si no nada.

PinotXa: ¿Entonces, somos perros? (CASADO et al. 84).

También Zepeto va prediciendo los cambios físicos y emocionales que localizará en su niña: 
Ella, cada día menos cibernética, ha crecido y al crecer ha empezado a entregar su sangre en cómodos plazos mensuales y llegado a una adolescencia llena de rabia, placer, desesperación e inseguridad; bullicio, aburrimiento, miedo y risas; llena de soledad, amistad, dolor y prisas... (CASADo et al. 85).

Dada la naturaleza de este género y el estilo en el que está escrita la obra, nos instalamos ante una reflexión sobre en qué medida se interrelacionan el mundo infantil y la creatividad surrealista, ya advertidos desde el subtítulo, que mezcla a Pinotxa con el beckettiano Godot (en este caso denominado Dogot).

En esta línea irracional brillan los espacios a los se nos traslada como Lividipool, Lividotel «Las Lilas» o los tiempos: «Son las PI 3,14», Neuropólitan Primavera del 7 1/2, «Verano del 23 PM», «17 horas PM, Crepúsculo siberiano en Makagascaire, Pedacitos rotos de corazones estallados» (CASADO et al. 94).

Así, en la obra conviven la poesía y el humor, la metáfora o la alegoría visual, como la del juego de la cuerda, que muestra a su vez uno de los momentos de interacción con el público.

\section{SOBRE DE COMUNIÓN}

Cuando comenzamos la lectura de De comunión (First communion), escrita por Carmen Gómez de la Bandera ${ }^{8}$, lo primero que nos sorprende es leer en el dramatis personae que las protagonistas, Mari Cruz y Mari Fe, son dos nińas de treinta y tantos a cuarenta años vestidas de comunión. Esta ruptura de lo verosímil nos sumerge ya de pleno en las aguas de la comedia.

La obra comienza mezclando la realidad histórica de España con la ficción irónica. Una voz en off del conocido NODO nos ubica en el mes de mayo de 1976 y anuncia que las dos niñas traviesas que lograron burlar el cordón policial que protegía el cadáver de Franco en la catedral de la Almudena para besar el excelentísimo rostro del caudillo hacen su primera comunión. Tras este documento sonoro entran Mari Cruz y Mari Fe y nos introducen en la ceremonia de su primera comunión.

Se establece así una estructura metateatral basada en dos niveles comunicativos, el de la ceremonia religiosa que obliga a las niñas a actuar siguiendo las pautas del rito, y el de los comentarios en aparte que ellas van haciendo durante el mismo.

En seguida entenderemos que Mari Cruz y Mari Fe están así porque le pidieron un milagro a santa María Goretti, una santa que prefirió la muerte antes que perder la virginidad. Rogaron no crecer, quedarse en el día más feliz de su vida, el de su primera comunión, para lo que la santa les exigió una oración y tres pelos de otro santo. La broma está servida en la copa de la ironía, porque es aquí cuando el espectador comprende que la acción de las niñas no estaba marcada por la devo-

${ }^{8}$ Carmen Gómez de la Bandera es doctora en Filología y licenciada en Arte dramático, actriz, investigadora y miembro del equipo gerente del Teatro de las Aguas. 
ción al caudillo, sino por el interés de arrancarle los tres pelos que necesitaban para su milagro, tal y como ellas nos cuentan:

Cruz: Mujer, era el primer santo que teníamos a mano. Y Sta M. ${ }^{a}$ Goretti lo dijo bien claro: «Para que se cumpla el milagro tenéis que tener tres pelos de un santo». ¡No me digas que no fue divertido acercarse al féretro, saltarse el cordón policial y a los guardias civiles que estaban llorando emocionados!

Fe: «Inocente trastada en la Almudena. Dos nińas logran burlar el cordón policial para besar emocionadamente el cadáver del Caudillo». Y... ¡Ahí pillamos los tres pelos!

Fe y Cruz: «Por estos tres pelos invocamos a tres santos: a Santa M. ${ }^{a}$ Goretti, San Franco y San Carrero Blanco» (121).

Por tanto, esta enésima repetición de la ceremonia de la comunión trazará el hilo conductor que servirá de engarce para la crítica de tipo social, política y religiosa enriquecida por la distancia que propicia la mirada ingenua de las niñas, como vemos, por ejemplo, en este comentario sobre los judíos:

CRUz: [...] y los judíos ya no van al infierno porque son amigos de un señor muy bueno que cambia de nombre muchas veces. Mira: primero se llamaba Clintón, luego se llamaba Bus y ahora se llama No va Más y que es muy importante y que manda casi tanto como Franco, pero que no se ha muerto. El malo, malo era Laden (121).

Pero como todos los conjuros pueden ser revertidos, también se puede parar este eterno retorno, por ello la comunión a la que estamos invitados tiene algo de especial: es la número trece mil ciento treinta, fecha en la que la santa Goretti les había indicado que podrían decidir saltar a la vida actual, en este caso a nuestro siglo. Surge así la necesidad de las niñas de explorar nuestra actualidad para valorar esta oferta. En este proceso brotará el conflicto entre ambas porque una de ellas no querrá salir; sin embargo, el foco de interés de esta creación no será tanto desenredarlo como el hacer un repaso de nuestra sociedad contemporánea a través del humor.

Si bien hay críticas directas a la institución religiosa o al propio dogma, lo habitual es que estas aparezcan insertas en un contexto político.

Entre las primeras hay alusiones a la pederastia:

FE: ¿`ú crees que el cura se toca?

Cruz: Claro, los curas lo pueden tocar todo: a los santos, a las santas y a los monaguillos, porque son sus amigos y porque son curas (CASADO et al. 112).

Al carácter amenazante del dogma religioso, o a la banalidad del rito eclesiástico consistente en una repetición vacía anacrónica o desprovista de sentido:

Fe y Cruz: Dios te salve, reina y madre.

FE: Estamos siendo abrasadas por el rayo divino.

Cruz: Dios te...

FE: Pero, ¿̨quién es ese dioste...?

Cruz: Pues debe ser alguien muy importante... Reina y madre de misericordia vida y dulzura. Dios te...

FE: Lo ves, otra vez dioste... (CASAdo et al. 114). 
Y entre las críticas mixtas destacaré un par de ejemplos. La réplica que anoto a continuación viene tras la reflexión de Mari Fe, cuando, informada, por su amiga sobre la supresión del purgatorio por el papa, se plantea el paradero de los que estaban purgándose:

Cruz: ¡Uf!, la mayoría. Ahora solo quedan en el cielo los muy buenos, muy buenos: Dios, la Virgen, Sta M. ${ }^{a}$ Goretti, el Ángel de la Guarda, Jesusito de mi vida y Franco. Y los muy malos muy malos en el infierno.

FE: Claro, los del «Contubernio Internacional» y los judíos y los masones y los comunistas porque nunca hicieron la Primera Comunión (CASADO et al. 109).

Aquí se mezcla la política internacional con la religión. Y en este otro el tema religioso se relaciona con el capitalismo neoliberal. Ya que ante la tesitura de cómo se van a ganar la vida en el siglo Xxi, Mari Cruz y Mari Fe visualizan distintas opciones de negocio como esta que combina el tema religioso con la crítica de una sociedad invadida por el mercado capitalista, siempre abierto a la absorción de nuevos consumidores:

CRUZ: ¿Qué te parece hacer publicidad del asunto como hicieron las de Fátima? Y nosotras de abadesas perpetuas. Ya lo estoy viendo: «La Abadía de las Santas nińas de Madrid, Mari Fe y Mari Cruz». Novenas, medallas, libritos, velitas, rosarios, tarjetas, dedales, souvenirs...

FE: Inciensos, votos, exvotos, huesos, ceras, sangres licuadas, momias de santos y relicarios... ¡Qué bonito! ¡Todos hechos en China con nuestra imagen dentro!

CRUZ: De nuevo no piensas en el negocio. Nos haremos ricas. Ya sé, inventaremos la bioética aplicada a los procesos religiosos: ¿Qué te parece si al pan de oblea sin levadura de a diario le añadimos fibra activa y calcio, para que se note por dentro y sea más profunda y espiritual?

FE: ¡Qué lista eres Cruz, acabas de inventar la biohostia! (131).

De aquí arranca uno de los momentos más divertidos de la obra porque las chicas sucumben poseídas de un éxtasis creativo que prosigue con la invención de una salsa de tomate que santifica llamada Kepchup Christ y culmina con la parodia del salmo responsorial del ritual eucarístico en versión neoliberal:

CRUz: Ahora yo, Vitaminas «Fortipluf» después de una larga jornada de trabajo, para por fin dejar de descansar.

Cruz y Fe: Te lo pido, cómpralo.

Fe: Hipoteca Blanca Jdt direct. Jo De Te: Alta rentabilidad en ruinas ajenas y ganancias propias sin comisiones, ni depósitos..., de cadáveres.

Cruz y Fe: Te lo pido, cómpralo.

FE: Barritas Anorexil, sin azúcar, sin calorías. Sin barritas.

Cruz: Te lo pido, cómpralo (CASAdo et al. 125).

En el contexto de la política española la institución monárquica es un blanco reiterado. En la siguiente cita se llega a la misma partiendo de la burla de esa educación machista que inculca en el imaginario femenino la existencia del príncipe azul: 
FE: Príncipes de todos los colores, razas y religiones...

Cruz: Príncipes azules.

FE: Para ponerte morada.

Cruz: Príncipes rojos.

FE: Ah, no, que a los príncipes no les sienta bien el rojo...

CRuz: Príncipes dorados, príncipes marfil, príncipes perla.

Príncipes verdes...

FE: No verde tampoco, porque te puede salir rana.

Cruz: No, tonta, si con un besito se puede transformar a un príncipe en cualquier cosa, incluso en un rey pueblerino y republicano, hacerse campechano y popular y reproducirse en el poder.

FE: La suegra real, la nuera real, los primos reales, los sobrinos reales, los cuñados reales, los consuegros reales, los compadres, los concuñados reales, Ciudad Real, el águila real, el buitre real, el pavo real, y hasta la coneja real (CASAdo et al. 120).

Por supuesto que el feminismo también está presente para desmontar los cánones fijados sobre el cuerpo de la mujer:

Cruz: La celulitis rebelde y el michelín agresivo nos atacan.

FE: ¡Qué horror! Son pruebas públicas y evidentes de nuestra rápida transición a la vida adulta sin pasar por la adolescencia ni nada (CASADo et al. 116).

Apenas nadie sale ileso de este jolgorio crítico. El individuo de nuestra sociedad aparece como un ser enajenado, frívolo, consumista, egoísta, estresado...

FE: (Con los oidos tapados. Canta). ii Quisiera ser tan alta como la luna!! (A Cruz). ¡Quisiera que me dejes hablar, hablar y hablar, y vivir enganchada a un móvil! Muy pequeñito, con cámara de fotos para llevar fotos de tu mamá que es muy guapa, y juegos de esos de matar gente. ¿Qué quieres, que sea mayor para tener que esperar el fin de semana para emborracharme, como mi padre? ¿Y qué quieres, que me haga mayor y tenga que tragar un montón de pastillas, como mi madre? Pastillas de colores: la amarilla para dormir, la verde para despertarse, la blanca para no sentir y la gris para no aplatanarse... Quisiera, quisiera contarte lo que dice mi padre: «Esta niña es tonta, pégale un sopapo para que aprenda, ha salido a tu madre. ¡La muy imbécil ha tenido que salir a la suegra! Toma tú también, por lista, por 'drogalista'. Pero si es que no tienes ni sentido ni humor... Sí, sí, anda, tómate otra pildorita y te quedas dormida hasta el día del juicio..., y dale una a ésta a ver si se le quita esa cara de pánfila... Y con suerte cambiamos de cuento y se queda como la Bella Durmiente, que así despierta parece más bien la Bestia... Porque nena, tú de 'Bella', nada... Eh, ¿qué pasa? ¿No te hace gracia, adefesio...? (Silencio). Yo no sigo jugando a este juego. ¡No, no y no! ¡Yo no quiero ser mayor, yo no quiero ser como papá y mamá... Decidido, ¡volvemos a nuestro milagro! (CASAdo et al. 118).

Y para este no-individuo el modelo cultural es todo lo que sale de la televisión que se erige en máximo símbolo de medio de comunicación de masas:

Cruz: ¡Informática al poder!

¡Que viva la información! 
Seamos partícipes todos

de la globalización.

Fútbol, concursos, anuncios,

la prosperidad mayor.

Permanezcamos unidos

gracias al televisor (CASADo et al. 122).

A este respecto hay un momento del texto en el que se juega a enlazar títulos de programas televisivos de los años setenta engastados en el diálogo que adquieren un nuevo sentido.

Como vemos, el lenguaje fluye enriquecido por el chiste, la ironía, el sarcasmo, la caricatura, la poesía, los juegos de palabras, la parodia... que lindan con el surrealismo y el absurdo, como intuyen las propias protagonistas:

CRUz: Parecemos una obra del absurdo. Esperando, esperando qué. ¿Esperando a Godot?

FE: ¿¿Y quién es ese Godot?

Cruz: No sé, lo he oído en algún sitio pero debe ser alguien al que espera mucha gente.

FE: A lo mejor es amigo de Dioste... (CASAdo et al. 127).

Pese al poco desarrollo que se da al conflicto sobre el desacuerdo entre las nińas, el montaje está transido de movimiento, al que contribuye la constante apelación al público, que entra de lleno en el juego de las niñas, ya lanzándoles a su ceremonia de comunión, ya tildándoles de extraterrestres que han abducido a sus padres y familiares, ya lanzándoles preguntas incómodas.

Impregnado de nuestra cosmovisión líquida el montaje será flexible, adaptándose al local, al día o a la respuesta del público al que se ofrezca. En este sentido, también en la línea brechtiana, una nueva ruptura de la cuarta pared hace que las actrices se desvistan del personaje para ofrecer dos posibilidades de final de la obra, la que sería coherente con el desarrollo dramático o la de la pura apetencia.

\section{ANÓNIMA EMPATÍA}

Anónima empatía (Anonymous Empathy) aparece en el índice del volumen como una "tragedia a la griega con coros rap en tres actos». Marina Castińeira" construye una obra híbrida, un experimento teatral bicéfalo que pretende aunar dos tiempos: la Grecia de Pericles y nuestra contemporaneidad. La denominación de tragedia, en mi opinión, se refiere al tono general de la obra, ya que mueren la mitad de

9 Marina Castiñeira Ezquerra es doctora en Filosofía, ensayista y traductora. Además, es fundadora de la compañía Manápatós. 
los personajes: Bárbara mata a Theron, Anastasia asesina a Bárbara, Timeus mata a Anastasia y se suicida, aunque luego es rescatado por un criado.

En primer lugar, la fábula tiene poco que ver con el mito, como mucho podemos relacionarla con el motivo folclórico, tan de éxito en los siglos de oro sobre el curioso impertinente, con la particularidad de que ahora son las amigas las que se retan y ponen a prueba la fidelidad del varón. Aquí Bárbara le propone a Anastasia tentar a su pareja Theron, por lo que las siguientes palabras podrían leerse como una especie de la hamartia:

AnAstasia: ¿Quieres jugar, eh? La verdad es que no le vendría mal llevarse algún chasco, y estoy tan aburrida... Juguemos un poco. Movamos ficha (rien) (CASADO et al. 165).

No se alcanza el tono grave, solemne o trascendente de la tragedia, ni estamos ante un personaje que, obligado a elegir, se encuentra ante un dilema, ni la autora adopta una actitud de «rodillas» frente a sus criaturas, ya que estas, en lugar de exhibir una condición superior a la condición humana, son, por el contrario, demasiado humanas, demasiado de carne y hueso, como diría Unamuno. Son seres conducidos por las pasiones, más próximos a los protagonistas del drama romántico y del melodrama, si tenemos en cuenta el papel que juega la música en este texto.

Los nombres de los personajes son simbólicos en un deseo de revelar en parte su naturaleza: Sandra es la ayudante de la humanidad, Bárbara es la extranjera, Timeus el perfecto, Niké la victoria, Zoe la vida, etc. Sin embargo, no son héroes, ni pertenecen a la alta nobleza como propugnaba Aristóteles, todo lo más se nos cuenta que, en el pasado, Hipólito, padre de Theron, gozaba de un status económico superior que perdió por culpa de la guerra y que le obligó a trabajar como maestro, y que la familia de su discípulo Timeus, gracias a la especulación, experimentó el proceso contrario.

Los cuatro raps que enmarcan y comentan la acción podrían hacer las veces de coro, y poseen la difícil tarea de lograr una fusión temporal al participar sus integrantes de las dos cronologías: Theron, Timeus, Bárbara y Anastasia son jóvenes que actúan tanto en la Grecia clásica de Pericles como en nuestra contemporaneidad.

El marbete de «a la griega» destaca uno de los ingredientes más sobresalientes del texto, ya que la obra rebosa información sobre la vida en la Grecia clásica.

El objetivo del texto es hacer una comparación entre los dos tiempos para verificar si la humanidad ha logrado ese aludido progreso en el que ingenuamente creían los hombres de la Ilustración. Sin embargo, además de que estamos ante una «tragedia», desde el primer rap se nos anticipa el mensaje del eterno retorno: «Esta es la historia, entérate, se retuerce, se recicla, lo vas a ver» (202) y acaba con otro rap cantado por los personajes ya muertos, que nos advierten de que el hallazgo de una solución para cambiar la vida no puede llegar una vez que hemos muerto.

El discurso teatral se articula mediante la convención de alternar la escritura de dos epístolas de la pluma de los dos personajes principales, Hipólito y Sandra, un matrimonio que no se comunica entre sí: él le escribe a su pupilo, al que ama, y ella se dirige a su hija muerta inundando sus palabras de su soledad y angustia por la pérdida de su niña, cuya imagen proyecta sobre su nieta Zoe: 
SANDra: Para informar a los vecinos de tu sexo, colocamos en la puerta de casa una banda de lana, no la rama de olivo que corresponde a un nacido varón. Y, si por tu padre fuese, te habríamos sacado en un cacharro de barro a la puerta de casa, sin prodigarte atenciones ni alimentos, como si fueras un hijo ilegítimo o un ser deforme (CASADO et al. 141).

A través de estas epístolas se van trasluciendo aspectos curiosos y costumbres de la vida de la Grecia clásica, por ejemplo, en lo referente a la diferente educación de hombres y mujeres, a los ritos nupciales, a la educación, al funcionamiento de la casa, etc.

SANDRA: A escribir, a calcular y a tañer un poco el arpa, la cítara y el tamboril para las ceremonias orgiásticas también te habría enseńado yo. Porque las mujeres no asistimos a las escuelas, como hacen los hombres, y no existe nada parecido, en la Atenas de hoy, a ese instituto de educación para las jóvenes de alto nacimiento que la poetisa Safo dirigió en la isla de Lesbos hace ya un siglo (CASAdo et al. 144).

La situación de la mujer es el foco de atención. Sandra es una mujer frustrada en su matrimonio, consumida por el sufrimiento y la soledad y sometida a Hipólito, un marido homosexual que está enamorado del joven amigo de su hijo. Su nuera Anastasia vive ocupada en cuidar de su bebé, sometida a los deseos de su pareja y sin un proyecto de vida propio en el que no participe Theron, quien en un gesto de prepotencia patriarcal viola a su amiga Bárbara. Bárbara es una muchacha extranjera que se siente rechazada por diferente y que está interesada en Timeus, un joven narcisista que parece que solo quiere comprometerse consigo mismo pero que veremos está enamorado de su amigo Theron.

Por las palabras de Sandra deducimos que el modelo femenino preferido por los hombres griegos como esposa nos resulta bastante familiar:

SANDRA: La filosofía es para los hombres, mientras que lo adecuado para nosotras, en cambio, es ver lo menos posible, oír lo menos posible, preguntar lo menos posible: tal es el lema acuñado para asegurar nuestra virtud (CASADO et al. 145).

Sandra nos pinta un universo femenino que hemos aprendido en muchos argumentos del teatro siglo de oro español o sin ir más lejos en ese Si de las niñas mediante el que Leandro Fernández de Moratín se lamentaba del forzamiento por parte de los progenitores al matrimonio de sus hijas.

SANDRA: Ay Niké, Niké, mi niña bonita, (rie). ¡Qué cosas me preguntas! ¿Que para qué le sirve la ciudadanía a una mujer? Hoy por hoy, la ciudadanía sólo le sirve a una mujer para poder contraer matrimonio con un ciudadano de pleno derecho que nos elige nuestro padre o, a falta de él, hermano, abuelo, tutor... Casi cualquiera vale para decidirlo por ti. Yo no me casé joven: contaba ya (enfatiza). Dieciséis años, mientras que tu padre tenía entonces (enfatiza). Sólo veinticinco. Pero tu abuelo paterno deseaba ver nietos, y me eligió a mí aunque jamás me había visto, recluida como estaba en la casa, ajena a la vida pública y a los hombres incluso de mi propia familia. Bueno, es lo normal. Se trata de asegurar la descendencia. (Rie). 
¿No creerás que lo importante del matrimonio sea la atracción o el amor entre los esposos? Ay, la dote, la dote... reforzar los lazos entre familias (CASADO et al. 155).

Como la mujer en nuestra cultura occidental hasta no hace mucho, tampoco era libre la mujer griega:

SANDRA: Por supuesto, tampoco conocemos las palestras. ¡Toda nuestra vida se desenvuelve en la quietud del hogar, segregada del contacto con los hombres! (Deja la pluma). ¡Cuán diversas son nuestras costumbres de las de las jóvenes de Esparta, que realizan ejercicios físicos al aire libre, junto a los muchachos (se levanta la túnica dejando ver las piernas con gesto impúdico) mostrando sus piernas desnudas bajo sus cortos peplos flotantes! Es que no reciben esa educación virtuosa que tanto alaban los atenienses en sus mujeres. Lo único que nosotras tenemos en común con ellas, por desgracia, es la carencia de derechos políticos y jurídicos, igual que si fuéramos esclavos (CASADO et al. 146).

No obstante, en la trama ubicada en nuestra contemporaneidad Bárbara y Anastasia encarnan dos modelos distintos de mujer, la primera más independiente y segura de sí, que recrimina a su amiga por su dependencia afectiva de Theron, instándola a labrarse un futuro propio por el que discuten y de donde le brota a Bárbara la peregrina de idea de tentar a su marido para demostrarle que es un hombre que no vale en absoluto la pena:

Bárbara: Pues yo en cambio lo que no quiero es meterme en casa a cocinar, a planchar camisas... ¡hay que saber vivir! En el colegio querías ser médico (CASADO et al. 145).

Con el feminismo se enlazan otros temas como el de la homosexualidad, el racismo, la maternidad, el amor no correspondido, las dependencias afectivas, la soledad, la falta de proyectos de algunos jóvenes en la vida, las consecuencias de la guerra...

A este respecto, la homosexualidad era una práctica común en Grecia, pero solo entre los hombres, sobre todo en la relación entre maestro y discípulo, quienes compatibilizaban perfectamente sus prácticas homosexuales con el matrimonio.

Ya hemos sugerido que de fondo late el panorama político y social, cuando, en su carta a Timeus, Hipólito, condena la Atenas de Pericles castigada por la guerra y por la peste que ha provocado la injusticia de desproveer de todo a algunos y enriquecer a los especuladores, como al padre de Timeus.

Por supuesto no puede faltar el tema del racismo, revelador del miedo que tenemos a lo desconocido, de la propia inseguridad y de la necesidad de sentir que se pertenece al lugar donde se vive:

BÁrbara: (a Timeus). ¿ YY quién eres tú, moro de mierda?!

Timeus: (a BÁrbarA). ¡Yo soy tan de aquí como tú, estúpida, he nacido en este país, mi nombre es de aquí, he estudiado en esta ciudad y soy mejor que tú! Mi acento es ateniense, y tú farfullas con ese acento horrible de Esparta! 
BÁrbara: (a Timeus). ¡Pero yo soy griega y tú no! No importa lo que hagas, ni lo que te creas que eres. ¡Siempre serás un moro de mierda, no hay más que verte! (CASAdo et al. 153).

Para concluir, pese a que esta hermandad de tiempos le sirve a la autora para conducirnos a la patética conclusión de que todavía hay muchos problemas que la sociedad humana debe resolver, la obra termina con un rap si pleno de ironía también de esperanza al incitar a los vivos a luchar por aquel lema olvidado de la libertad, igualdad y fraternidad.

Tras esta larga reseña y breve análisis se deduce que Flotar sin máscara, a pesar de su diversidad en cuanto a géneros y estilos, es una obra coherente con la labor de la Asociación Marías Guerreras, orientada claramente a la crítica social, destacando siempre el problema de la mujer, y que revela una disconformidad con una realidad circundante que se nutre de la desigualdad, del engaño y del abuso de poder. 


\section{REFERENCIAS BIBLIOGRÁFICAS}

Bauman, Zygmunt. Vida líquida. Barcelona: Paidós, 2010.

Casado, Alicia (ed.). Teatro lésbico. Madrid: Editorial Fundamentos, 2018.

Casado, Alicia, Castiñeira, Marina, G. de la Bandera, Carmen, Ortiga, Blanca y Reiz, Margarita. Flotar sin máscara. Cinco obras de teatro de mujeres. Edición bilingüe español-inglés. Madrid: Ediciones irreverentes, 2018.

CoHen, Richard. Comprender y sanar la homosexualidad. Madrid: Libroslibres, 2004. https://www. academia.edu/17125368/Comprender-y-sanar-la-homosexualidad-RICHAR $\overline{\mathrm{D}-\mathrm{COHEN}}$.

http://www.mariasguerreras.es/. 